\title{
The treatment of obesity with personalized nutrition according to their hormonal body type and metabolic type
}

\begin{abstract}
Obesity prevalence is increasing. 2/3 of Hungarian society is currently overweight or obese, and nutrition plays a significant role in it. There are countless diets to deal with this, so the choice is a common problem.

Aim: To examine the metabolic type and the hormonal body type and to assess the occurrence of the types.

Method: The assignment is based on the Metabolic Typing Diet questionnaire, and a condition for belonging to a hormonal body type is that we have at least six qualities that are specific to that type. We compared both the hormonal body types and metabolic types nutrition with their own recommendations considering BMI. 64 people was asked, who was at least 18 years old.

Results: The most common metabolic type is the mixed type by $70 \%$, followed by the protein type by $18 \%$ and the carbohydrate type by $12 \%$. For hormonal body types, the adrenal type is $44 \%$, the gonad type is $25 \%$, the thyroid type is $22 \%$, and the pituitary gland type is $9 \%$. When we consider both of our types and BMI, we can say that there was no significant difference between the recommended carbohyrate intake among the overweight/obese thyroid type and their metabolic types $(n=10)$. This was similar to normal body mass index $(n=4)(p>0.05)$. The overweight / obese oestro type $(n=10)$ and their metabolic types had a significant difference between the intake and the recommended fat ratio; $(\mathrm{p}=0.0001)$ This was similar to normal body mass index $(n=6)(p=0,0001)$. The overweight / obese supra type $(n=22)$ and their metabolic types had a significant difference between the ratio of protein intake and recommendaton $(\mathrm{P}<0.05)$, it was significantly higher $(\mathrm{P}<0.0001)$. In normal body mass index $(\mathrm{n}=6)$ there was no significant difference.

Conclusion: Nutrition is determined by our types of preferences and differing from the recommendations is in many cases, but there are cases where there is no difference, the definition of the comparative base is complex, as we try to personalize the diet. There is a correlation between the intake of macronutrients (which would like to be decreased) of the metabolic types and BMI, so in most cases the hypotheses are mainly correct.The frequent occurrence of adrenal type and gonad type reflects the hungarian nutrition patterns, so most of us should pay more attention to decrease fat and animal products. The basic pillar of personalized medicine is that we do not think in schemas, so the needs of the individual within the type require more attention. The characteristics both of the types requires further research.
\end{abstract}

Keywords: overweight, obesity, hormonal body type, metabolic type

\section{Intorduction}

$2 / 3$ of Hungarian society is currently overweight or obese. $40 \%$ of men are overweight and $32 \%$ are obese, $32 \%$ of overweight and obesity in women in both cases, and the value increases with age. ${ }^{1}$ Among the OECD countries, Hungary is the fourth most obese country and on the top of the podium in Europe. ${ }^{2}$ Most of the mortality are due to inadequate nutrition, more than smoking-related deaths. ${ }^{3}$ As we see the nutritional status of Hungary, it can be said that there is an excessive amount of animal product and fat intake, while fruit, vegetable and cereal consumption is low. The dietary fiber intake is decreasing and sugar consumption is increasing. ${ }^{4}$ There are countless approaches to treat the obesity. There are many contradictory diets that prove workable for some, but not others, so it could be possible that everyone is right in some cases. Based on this we can see that the treatment should be personalized. David Zeevi researc focusing on postprandial glycemic response to personalize the diet To do this,
Volume 12 Issue 2 - 2019

\author{
Dorottya Zsálig, Gabriella Hegyi \\ Pecs University Health Science Faculty, Hungary
}

Correspondence: Hegyi Gabriella, Pecs University Health Science Faculty, Pecs, Vorosmarty u.4, Hungary, Emaildrhegyi@hu.inter.net

Received: February 24, 2019 | Published: March 21, 2019 the carbohydrate content and glycemic index were considered. There are great differences in the same foods in different people postprandal glucose levels that justify to comsumize the diet. ${ }^{5}$ The influence of the climate on human morphology is significant: the cooler the climate is, the larger the body mass, and the warmer the climate is, the leaner and the taller the body. ${ }^{6}$ Nutrition is related to our morphology, because our body type is hereditary and most likely the climate has specific dietary patterns. ${ }^{7}$ Based on these, eating according to our hormonal body type ${ }^{8}$ and metabolic type ${ }^{9}$ can be an interesting approach to diets.

\section{Method}

$\mathrm{N}=64$, aged at least 18 . Sampling is random and not representative. The $95 \%$ average confidence interval test compares the nutrition of hormonal body types to WHO recommendations, and the metabolic types nutrition with their recommendations according to The 
Metabolic Typing Diet. Considering the nutrition of both type to compare the normal bodyweight and overweight / obese nutrition to know how it differs from Metabolic Typing Diet recommendations. The hormonal body type is the baseline, and then we compare the 'limiting' macro-nutrient intake assigned to the hormonal body type with the recommendation of Metabolic Typing Diet according to our metabolic type. Linear regression is used to determine the correlation between the metabolic types and BMI according to the types increasable makronutrients. The data was collected in a questionnaire form, the nutrition status was measured in a one week dietary form, and processed with the help of the MyFitnessPal application. Nutrition status was determined by BMI.

\section{Results}

In terms of hormonal body types, the highest proportion of the adrenal (supra) type is present (44\%) among the respondents $(n=28)$. This type is followed by the gonads (oestro) type by $25 \%(\mathrm{n}=16)$, followed by the thyroid (para) type by $22 \%(n=14)$, and the pituitary (neuro) type by $9 \%(\mathrm{n}=6)$ (Figure 1$)$. The most common of the metabolic types - or nutritional types - is the mixed type $75 \%(n=48)$ followed by the carbohydrate type $(16 \%)(n=10)$, and finally the protein type $(9 \%)(n=6))$ (Figure 2). In men, the adrenal type was also the most prevalent in hormonal body types with $68 \%(n=17)$. This is followed by the thyroid type by $20 \%,(n=5)$, and the pituitary gland by $12 \%$ and $(n=3)$. None of the respondents included gonads (sex glands).

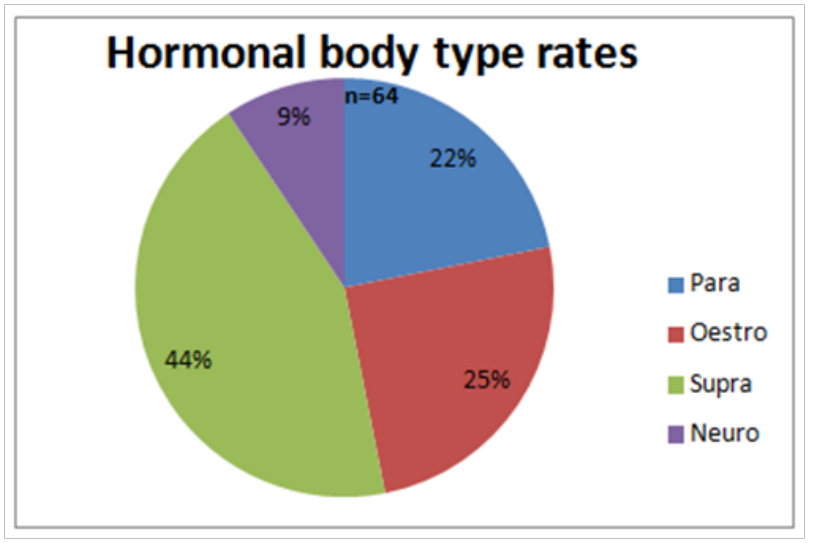

Figure I Abra Hormonal body type rates among 64 participants.

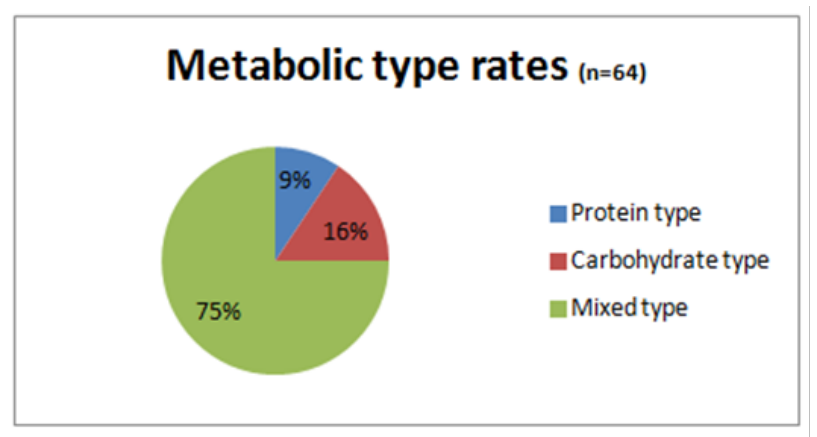

Figure 2 Abra Metabolic type rates among 64 participants.

The ratio in men of the mixed type is the highest with $78 \%(n=21)$, and the protein type follows with $15 \%(n=3)$ and finally the type of carbohydrate $(\mathrm{n}=2) .7 \%$. In women, the most common type of hormonal body type is $35 \%,(n=13)$ gonad type, followed by adrenal type $33 \%,(n=12)$. They follow the thyroid type by $27 \%$, $(n=10)$, and finally the pituitary gland by $5 \%(n=2)$. The proportion of women in the metabolism types is $11 \%$ protein type $(n=3), 16 \%$ carbohydrate type $(n=8)$ and $73 \%$ mixed type $(n=27)$. Most of the overweight and obese are out of the adrenal type of hormonal body types, but are also the most common among normal body mass indexes - besides the gonads type - but this is also due to the fact that otherwise it is the most common hormonal body type. Obesity did not include any type of thyroid gland, but this group appeared in a large number of overweight people. The prevalence of gonads is the most common in the overweight category.

\begin{tabular}{llll}
\hline \multicolumn{4}{l}{ Number of the hormonal body types in BMI categories $(\mathbf{n}=\mathbf{6 4})$} \\
\hline \multirow{3}{*}{ Para } & Obese & Overweight & Normal \\
Oestro & 0 & 10 & 4 \\
Supra & 2 & 8 & 6 \\
Neuro & 8 & 14 & 6 \\
\hline
\end{tabular}

Of the metabolic types, the mixed type represents the highest incidence for all BMI categories, which can also be justified by the fact that it is the most common. Carbohydrate types are not obese, only overweight or normal. Protein types are equally present in all categories.

\begin{tabular}{llll}
\multicolumn{4}{l}{ Number of the Metabolic types in BMI categories $(\mathbf{n}=64)$} \\
\hline Obese & Overweight & Normal \\
Fehérje típus & 2 & 2 & 2 \\
Szénhidrát típus & 0 & 6 & 4 \\
Egyensúlyi típus & 9 & 27 & 12 \\
\hline
\end{tabular}

\section{Body types and their macro-nutrient intake}

There is no significant difference in the rate of intake of one macronutrient at the thyroid type, as this type consumes $50 \mathrm{E} \%$ of carbohydrates, $29 \mathrm{E} \%$ of fat and $21 \mathrm{E} \%$ of protein, so it can be said almost the same as the recommendation, but the value of the intake is critical. Protein intake of gonad type was developed according to the recommendation, consuming $21 \%$ of it. There was no significant difference in carbohydrate intake, which was taken in $46 \mathrm{E} \%$. Fat intake was designed according to the pattern of the type, the members of the group consumed significantly more fat $(35 \mathrm{E} \%)$ than the recommendation would require. Regardless of the type characteristics of the adrenal type, protein consumption was not significantly higher (on average $22 \mathrm{E} \%$ ), but fat consumption was significantly higher $35 \mathrm{E} \%$ on average - and carbohydrate consumption was significantly lower with an average $41 \mathrm{E} \%$ intake.

In the pituitary gland, only the fat consumption was significantly higher, while there was no significant difference between the intake of other macronutrients and the recommendation.

\section{Hormonal body types and macronutrient intake}

Protein consumption does not differ significantly from none of the hormonal types (Figure 3).

Carbohydrate intake was significantly lower in the adrenal type only, with no significant difference in the other types (Figure 4). 


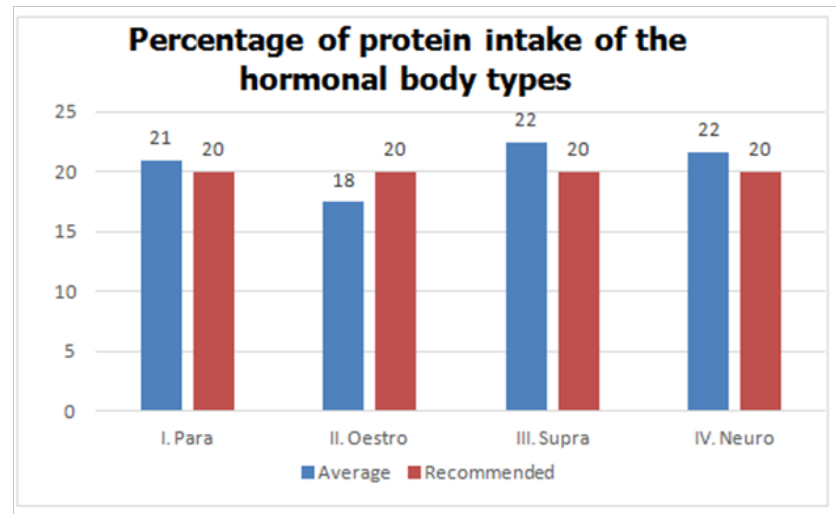

Figure 3 Percentage of protein intake of the hormonal body types.

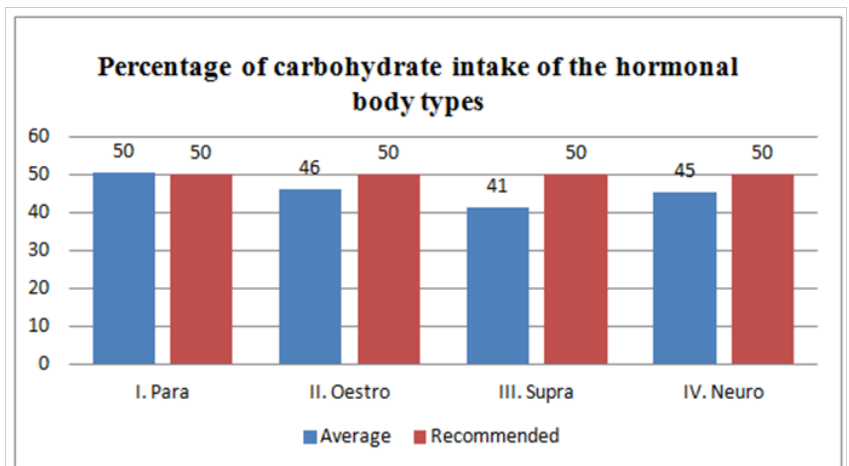

Figure 4 Percentage of carbohydrate intake of the hormonal body types.

There was no difference in the thyroid type in fat intake, but it was significantly higher in all other types (Figure 5).

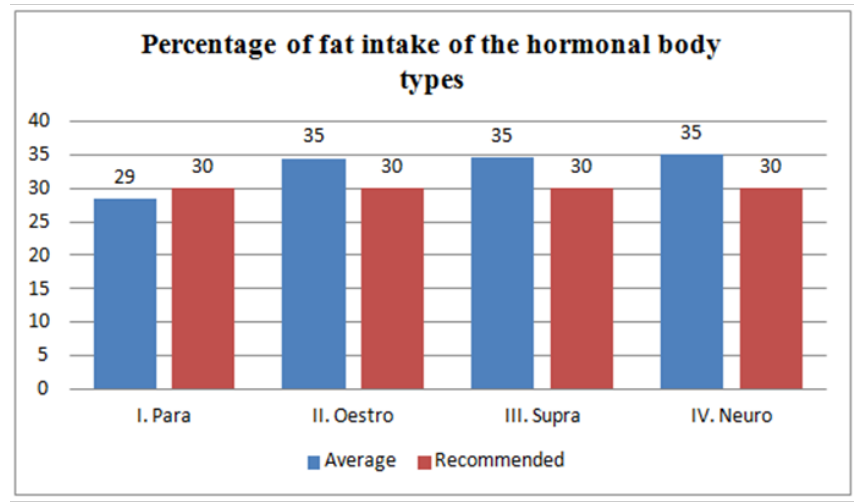

Figure 5 Percentage of fat intake of the hormonal body types.

\section{Both types and BMI}

Overweight or obese para type $(n=10)$, of which mixed type $(n=8)$, carbohydrate type $(\mathrm{n}=2)$. There was no significant difference between the intake and the recommended carbohydrate ratio in this group $(\mathrm{P}>0.05 ; \mathrm{P}=0.6)$

Normal weight para type $(n=4)$, of which mixed type $(n=3)$, carbohydrate type $(\mathrm{n}=1)$. There was no significant difference between the intake and the recommended carbohydrate ratio in this group $(\mathrm{P}>0.05 ; \mathrm{P}=0.6)$. Overweight or obese oestro type $(\mathrm{n}=10)$ of which mixed type $(n=9)$, carbohydrate type $(n=1)$. There was a significant difference between the intake and the recommended fat ratio $(\mathrm{P}<0.05)$ among this group it was in a significantly higher ratio $(\mathrm{p}=0.0005)$.
Normal weight oestro type $(n=6)$, of which equilibrium type $(n=2)$, carbohydrate type $(n=2)$, protein type $(n=1)$. There was a significant difference between the intake and the recommended fat ratio $(\mathrm{P}<0.05)$ among this group it was in a significantly higher ratio $(\mathrm{p}=0.0001)$.

Overweight or obese adrenal type $(n=22)$, of which mixed type $(n=29)$, carbohydrate type $(n=0)$, protein type $(n=3)$. There was a significant difference between the intake and recommended protein ratios $(\mathrm{P}<0.05)$ among this group it was in a significantly higher proportion $(\mathrm{P}<0.0001)$.

Normal weight supra type $(n=6)$, equilibrium type $(n=4)$, carbohydrate type $(n=1)$, protein type $(n=1)$. There was no significant difference between the intake and the recommended protein ratios $(\mathrm{P}>0.05 ; \mathrm{P}=0.1)$.

\section{Metabolic types macronutrient intake}

There was no significant difference between the average carbohydrate consumption rate of the protein type and the average protein consumption of the carbohydrate type, while the other two macronutrients showed a difference in both protein and carbohydrate type. In all cases, the mixed type had a significant difference between the intake and recommended ratios of all macronutrients (Figures 6-8).

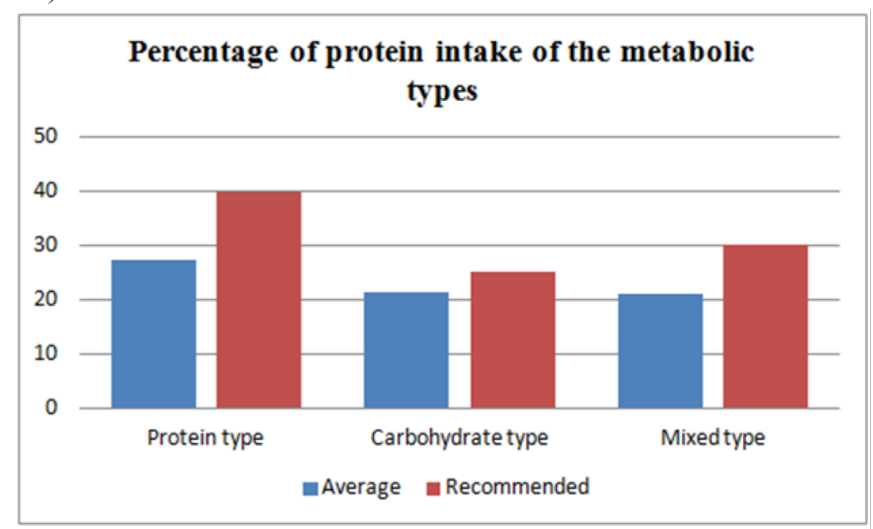

Figure 6 Percentage of protein intake of the metabolic types.

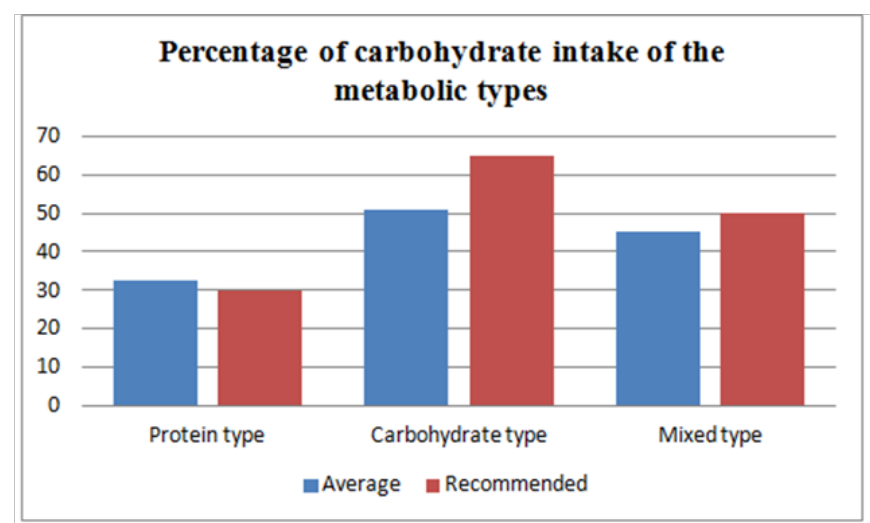

Figure 7 Percentage of carbohydrate intake of the metabolic types.

\section{BMI and metabolic types}

There is a positive strong correlation between carbohydrate intake of protein type and BMI $(\mathrm{r}=0.84)$, while the carbohydrate intake determines the BMI of protein types by $72 \%$. $(\mathrm{p}<0.05)(\mathrm{P}=0.06)$, so the correlation is significant.The protein type fat intake and BMI 
have a positive correlation $(\mathrm{r}=0.56)$. There is a positive correlation between carbohydrate fat intake and BMI ( $\mathrm{r}=0.39)$, so the increase in fat consumption in this type also increases BMI. There is a positive correlation between the protein intake of the type and BMI $(r=0.56)$, so the increase in protein consumption in this type also increases BMI. There is a positive correlation between carbohydrate intake of the mixed type and BMI $(\mathrm{r}=0.09)$. There is a positive correlation between protein intake of the mixed type and BMI $(r=0.2)$, so the increase in protein consumption in this type can increase BMI. There is a weak positive correlation between fat intake and $\mathrm{BMI}(\mathrm{r}=0.2)$, so the increase in fat consumption in this type can increase BMI.

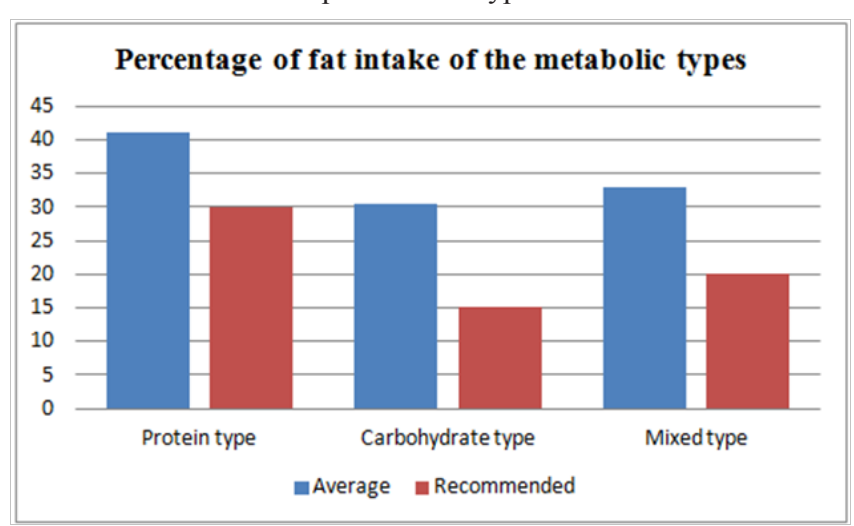

Figure 8 Percentage of fat intake of the metabolic types.

The correlations were only significant for the carbohydrate intake of the protein type (Appendix).

\section{Summary of the results of the hypotheses (Tables I-3)}

Table I The WHO guidelines are the basis for comparing hormonal body types, and the Metabolic Typing Diets are the the basis for metabolic types

Differences from the recommendation of macro nutrient intake

\begin{tabular}{lccc}
\hline & Protein & Carbohydrate & Fat \\
\hline Para & no difference & no difference & no difference \\
Oestro & no difference & lower intake & higher intake \\
Supra & no difference & lower intake & higher intake \\
Neuro & no difference & no difference & higher intake \\
Protein type & lower intake & no difference & higher intake \\
Carbohydrate type & no difference & lower intake & higher intake \\
Mixed type & lower intake & lower intake & higher intake \\
\hline
\end{tabular}

Conclusion: Nutrition is determined by our types of preferences and differing from the recommendations is in many cases, but there are cases where there is no difference, the definition of the comparative base is complex, as we try to personalize the diet. There are differences between both types of recommendations of the proportion of macronutrient consumption in most cases, both in hormonal body types and metabolic types. There is a correlation between the intake of macronutrients (which would like to be decreased) of the metabolic types and BMI, so in most cases the hypotheses are mainly correct.

Discussion: An interesting approach Eating according to our types can be an interesting approach to overcome obesity. The frequent occurrence of adrenal type and gonad type reflects the hungarian nutrition patterns, so most of us should pay more attention to decrease fat and animal products. The basic pillar of personalized medicine is that we do not think in schemas, so the needs of the individual within the type require more attention. The characteristics both of the types requires further research. Knowing our types can help us to become more familiar with the function of our bodies, observe its reactions and signals, so we can do for our health this way.

Table 2 Comparison of normal and overweight / obese members of hormonal body types and its metabolic types in the light of the macro-nutrient intake that is wolud like to be reduced, based on the recommendations of The Metabolic Typing Diet

Differences from the recommendation of macro nutrient intake considering both types

\begin{tabular}{|c|c|c|c|}
\hline & Protein & Carbohydrate & Fat \\
\hline $\begin{array}{l}\text { Overweight/obese } \\
\text { Para and its types }\end{array}$ & & no difference & \\
\hline $\begin{array}{l}\text { Normal BMI Para } \\
\text { and its types }\end{array}$ & & no difference & \\
\hline
\end{tabular}

Overweight/obese

Oestro

higher intake

Normal BMI

Oestro

higher intake

Overweight/obese

Supra

Normal BMI Supra higher intake

Table 3 Correlation between the intake of macro nutrients and BMI of the metabolic types

The correlation between some macronutrient intake and BMI in the metabolic types

\begin{tabular}{lccc}
\hline & Direction & $\mathbf{r}$ & Significance \\
\hline Protein type carbohydrate intake & positive & 0,85 & no \\
Carbohydrate type fat intake & positive & 0,39 & no \\
Mixed type carbohydrate intake & positive & 0,2 & no \\
Mixed type fat intake & positive & 0,09 & yes
\end{tabular}

\section{Acknowledgment}

None.

\section{Conflicts of interest}

Author declares there is no conflicts of interest.

\section{References}

1. Rurik I. A túlsúly és az elhízás trendje és prevalenciája Magyarországon. Orvosi Hetilap. 157(31):1248-1255.

2. https://www.oecd.org/els/health-systems/Obesity-Update-2017.pdf

3. Murray C. The state of US health, 1990-2010: burden of diseases, injuries, and risk factors. JAMA. 2013;310(6):591-608.

4. https://www.ksh.hu/docs/hun/xftp/stattukor/elelmfogy/elelmfogy10.pdf

5. Zeevi D. Personalized Nutrition by Prediction of Glycemic Responses. Cell. 2015;163(5):1079-1094.

6. Katzmarzyk P. Climatic influences on human body size and proportions: ecological adaptations and secular trends. Am J Phys Anthropol. 1998;106(4):483-503.

7. Peeters M. Heritability of somatotype components: a multivariate analysis. Int J Obes. 2007;31(8):1295-1301.

8. Hegyi G. Az enzimológia napjainkban. Praxis. 2016;25:(2):17-28.

9. Wolcott W. The Metabolic Typing Diet. Harmony: Broadway Books; 2002. p. 448. 